\title{
Antioxidant Supplementation and Kidney Function Status of Wistar Rats Following High Fat Diet-Streptozotocin (HFT-STZ) Induced Type 2 Diabetes
}

\author{
Chinaka NC ${ }^{1 *}$, Chuku LC ${ }^{2}$, Monago-Ighorodje CC $^{2}$ and Edeogu $\mathrm{O}^{1}$ \\ ${ }^{1}$ Department of Medical Biochemistry, Ebonyi State University, Abakaliki Nigeria \\ ${ }^{2}$ Department of Biochemistry, University of Port Harcourt, Rivers State, Nigeria
}

*Corresponding author: Chinaka NC, Department of Medical Biochemistry, Ebonyi State University, Abakaliki Nigeria, Tel: +2348039397700; Email:cn_chinaka@yahoo.com

Received Date: October 28, 2018; Accepted Date: November 26, 2018; Published Date: November 29, 2018

Citation: Chinaka NC, Chuku LC, Monago-Ighorodje CC, Edeogu O (2018) Antioxidant Supplementation and Kidney Function Status of Wistar Rats Following High Fat Diet-Streptozotocin (Hft-Stz) Induced Type 2 Diabetes. Biochem Mol Biol J Vol.4: No.3:24.

\section{Abstract}

The kidney function status of high fat diet-streptozotocin (HFD-STZ) induced NIDDM in albino rats fed antioxidant supplementation was monitored in vitro. Appropriate and recommended dietary allowed proportions of some potent antioxidant substances including: minerals, vitamins, $\alpha$-lipoic acid, phytochemicals and a D-ribose-Lcysteine conjugate were assembled together in corn oil and stored at $4^{\circ} \mathrm{C}$ for use. Kidney function indices were assayed using standard methods, kits and equipments. Data analysis was done with SPSS version 20.0 and significant level was set at $p \leq 0.05$. There were a total of five study groups with 10 rats each. Immediately after the induction of diabetes with HFD-STZ combination, treatment commenced and lasted for a total of 12 weeks, and analysis using serum was carried out at the $4^{\text {th }}, 8^{\text {th }}$ and $12^{\text {th }}$ week of the study. Results obtained from the kidney function status investigation indicates that there was significant decrease $(p \leq 0.05)$ in serum urea levels of the treated groups when compared to the controls (normal and diabetic) and this decrease was consistent as the treatment progressed. Serum creatinine, biocarbonate and potassium levels of both the treated and normal control groups where not statistically different $(p \geq 0.05$ ) when compared with the diabetic control group which increased steadily for creatinine and biocarbonate, but inconsistent for potassium level within the treatment duration. However, there was a significant increase $(p \leq 0.05)$ in serum sodium and chloride levels of the treated and normal control groups, when compared with the diabetic control group respectively. The observed increase was consistent with treatment duration. The results therefore suggest that the antioxidant supplement might have a restorative effect on kidney function and also enhance effective electrolyte balance and control for easy movement of ions across cell membrane.

Keywords: Biocarbonate; Creatinine; Electrolyes; Urea

\section{Introduction}

Diabetes mellitus, a metabolic disease associated with relatively low or absolute deficiency of insulin secretion is the primary cause of diabetic kidney disease (DKD). Diabetic kidney disease progression as one of the critical problems resulting from diabetes mellitus is associated with complications such as retinopathy, neuropathy, hepatopathy, nephropathy and cardiomyopathy, which are primary cause of morbidity and mortality worldwide [1-4]. Hyperglycemiainduced oxidative stress has been reported as one of the links between diabetes and diabetic complications ranging from endothelial dysfunction, insulin resistance, and alterations in the proportion and functions of pancreatic $\beta$-cells and ultimately leads to diabetic microvascular and macrovascular complications $[5,6]$. Hence, glucose oxidation, protein glycosylation and lipid peroxidation are as a result of free radical generation leading to increased reactive oxygen species (ROS). Under physiological conditions, ROS plays an important role in cell signaling implicated in proliferation, differentiation, apoptosis, and immune defense in various cell types, as well as renal cells [7]. However, overproduction of ROS in the kidney under pathological conditions is implicated in renal inflammation, affecting renal structure and function and subsequently leading to end-stage renal disease (ESRD). Chronic renal failure associated with diabetes has increasingly been recognised as a leading source of health concern.

However, oxidative stress associated with free radical generation and reactive oxygen species can be attributed to reduction in antioxidant activity.

Under physiological conditions, both endogenous and exogenous antioxidants interact with these oxidants to counteract the oxidative damage to cells [8]. The antioxidant defense mechanisms include superoxide dismutase (SOD), manganese SOD and copper/zinc SOD; glutathione system: glutathione peroxidase and glutathione reductase; catalase; and coenzyme Q. Antioxidant enzymes mainly convert ROS into nonreactive oxygen molecules, ultimately forming water. The entire antioxidant redox system mainly utilizes NADPH as a chemical reductant, which is mostly produced by glucose-6phosphate dehydrogenase [9]. 
The knowledge and use of key and important antioxidants such as glutathione, vitamin A, C and $\mathrm{E}$ in finding modalities for greater understanding on the treatment of diabetic kidney disease and other related complications is vital. Focus on the composition, synthesis and role of glutathione in the understanding of diabetes induced oxidative stress and its complications through different signaling pathways as well as ROS formation attributed to the activation of various downstream signaling cascade affecting structural and functional changes in kidney is of great importance to the management and treatment of diabetic kidney disease and diabetes mellitus in general. A study on the administration of antioxidant agents and its ability to restore the antioxidant defense system thereby preventing ROS mediated injuries is necessary.

\section{Methods}

\section{Animal care}

Wistar rats aged 3-4 weeks (70-110 g) purchased from the animal house of the Faculty of Pharmacy and relocated to the animal house of the Department of Biochemistry, Madonna University, Nigeria, Elele campus, Rivers State were used for the study. They were housed in well ventilated cages with access to water and food (chow) ad libitum. The animals were grouped into five with 10 rats each in stainless steel cages (34 $\times 47 \times 18 \mathrm{~cm}$ ) with soft wood shavings as bedding and maintained under normal laboratory conditions (temperature $24-28^{\circ} \mathrm{C}$, relative humidity $60-70 \%$, and 12 hour light-dark cycle). All animals used in this study were treated in conformity to the National Institute of Health (NIH) guidelines for handling laboratory animals.

\section{Preparation of high fat diet}

The high fat diet (HFD) was prepared according to the method of Srinivasan et al. [10], using growers mash $(60 \mathrm{~g} / \mathrm{kg})$, lard $(20 \mathrm{~g} / \mathrm{kg})$ and sucrose $(20 \mathrm{~g} / \mathrm{kg})$ in the ratio of $3: 1: 1$ respectively. The diet was carefully homogenized and pelleted, then fed to the animals with exception to the normal control group.

\section{Preparation of antioxidant supplement}

Recommended proportions of some antioxidant rich substances which include; vitamins $A(14.3 \mathrm{mcg} / \mathrm{kg}$ bw $), B_{3}$ $(0.214 \mathrm{mg} / \mathrm{kg} \mathrm{bw}), B_{6}(0.03 \mathrm{mg} / \mathrm{kg} \mathrm{bw}), B_{12}(0.03 \mathrm{mg} / \mathrm{kg} \mathrm{bw}), C$ $(0.9 \mathrm{mg} / \mathrm{kg} \mathrm{bw})$ and $\mathrm{E}(0.14 \mathrm{mg} / \mathrm{kg} \mathrm{bw})$; minerals like calcium (11.4 mg/kg bw), selenium (0.79 mcg/kg bw), chromium $(0.2$ $\mathrm{mg} / \mathrm{kg} \mathrm{bw})$, magnesium $(1.9 \mathrm{mg} / \mathrm{kg} \mathrm{bw})$, potassium $(0.05 \mathrm{~g} / \mathrm{kg}$ bw) and zinc (0.07 mg/kg bw), $\alpha$-lipoic acid $(8.57 \mathrm{mg} / \mathrm{kg} \mathrm{bw})$, cinnamon powder (43 $\mathrm{mg} / \mathrm{kg} \mathrm{bw})$, curcumin [Meriva ${ }^{\oplus}$ ] (3 $\mathrm{mg} / \mathrm{kg} \mathrm{bw})$, cordyceps $(7.5 \mathrm{mg} / \mathrm{kg} \mathrm{bw})$, resveratrol $(0.5 \mathrm{mg} / \mathrm{kg}$ bw), quercetin (2.5 mg/kg bw), D-ribose-L-cysteine [Ribocine ${ }^{\circledR}$ ] ( $30 \mathrm{mg} / \mathrm{kg} \mathrm{bw}$ ) were pulled together in corn oil and stored at $40 \mathrm{C}$ for use.

\section{Induction of type 2 diabetes mellitus}

Type 2 diabetes mellitus was experimentally modeled in the animals (with the exception of normal control group) by eight [8] weeks feeding of high fat diet, after which a single dose IP injection of $35 \mathrm{mg} / \mathrm{kg}$ body weight of streptozotocin was administered.

\section{Treatment}

Treatment with standard drug and antioxidant supplement commenced 7 days after fasting blood glucose levels were analysed and hyperglycaemia established (Table 1) The treatment lasted for a period of 12 weeks with analysis carried out on the $4^{\text {th }}, 8^{\text {th }}$ and $12^{\text {th }}$ week of study.

Table 1 Grouping and feeding illustration.

\begin{tabular}{|c|c|c|c|c|c|}
\hline Treatment key & 1 & 2 & 3 & 4 & 5 \\
\hline No. of rats per group & 10 & 10 & 10 & 10 & 10 \\
\hline Feed + water (Normal control) & + & - & - & - & - \\
\hline $\begin{array}{l}\mathrm{HFD}+\mathrm{STZ}(35 \mathrm{mg} / \mathrm{kg}) \text { (Diabetic } \\
\text { control) }\end{array}$ & - & + & - & - & - \\
\hline $\begin{array}{l}\text { Diabetes } \\
\text { (Actovista) }\end{array}$ & - & - & + & - & - \\
\hline $\begin{array}{l}\text { Diabetes + AS (antioxidant } \\
\text { supplement) }\end{array}$ & - & - & - & + & - \\
\hline 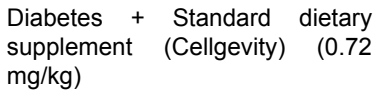 & - & - & - & - & + \\
\hline
\end{tabular}

\section{Assays}

The serum urea level was estimated using the method of Weatherburn [11], and serum creatinine level by the method of Bartels and Bohmer [12]. The serum electrolyte levels assayed for were Biocarbonate $\left(\mathrm{HCO}_{3}\right)$ by the method of Forrester et al. [13], Potassium $\left(\mathrm{K}^{+}\right)$and sodium $\left(\mathrm{Na}^{+}\right)$were by the method of Henry [14], and chloride $\left(\mathrm{Cl}^{-}\right)$was determined according to the method of Tietz [15].

\section{Statistical Analysis}

Data obtained from the study was analysed using the statistical package for social sciences (SPSS) version 20.0 for windows (SPSS Institute, Inc., Chicago, IL). One-way analysis of variance (ANOVA) was used to compare means, followed by the Tukey's test correction.

Values were considered significant at $p \leq 0.05$. Post hoc multiple comparisons and descriptives for the differences between groups were established by least significance differences (LSD). All the data are expressed as Mean \pm Standard Error of the Mean (SEM). 


\section{Results}

As shown in Table 2, at the $4^{\text {th }}$ and $8^{\text {th }}$ weeks of treatment, the serum urea levels were significantly higher $(p \leq 0.05)$ in the diabetic control group $(102.37 \pm 6.48,86.27 \pm 20.84$ and 76.38 \pm 0.38 ) compared to the normal control group (55.44 \pm 0.67 , $60.17 \pm 2.65$ and $55.31 \pm 0.31$ ) as well as the diabetic groupss treated with actovista $(64.51 \pm 2.33,33.55 \pm 6.42$ and $50.34 \pm$ $0.34)$, antioxidant supplement $(68.28 \pm 3.14,62.81 \pm 3.81$ and $26.57 \pm 4.88)$ and RiboCeine ${ }^{\circledast}(74.09 \pm 3.03,37.11 \pm 2.86$ and $27.20 \pm 3.30)$ respectively. Serum urea levels were significantly lower $(p \leq 0.05)$ in the group administered actovista compared to those that received the antioxidant supplements after the $4^{\text {th }}$ week.

Table 2 Serum urea level in normal and HFD-STZ induced NIDDM in albino rats administered antioxidant supplement.

\begin{tabular}{|l|l|l|l|}
\hline Urea & Week 4 & Week 8 & Week 12 \\
\hline GP 1 & $55.44 \pm 0.67$ & $60.17 \pm 2.65$ & $76.31 \pm 0.31$ \\
\hline GP 2 & $102.37 \pm 6.48^{\mathrm{a}}$ & $86.27 \pm 20.84^{\mathrm{a}}$ & $50.38^{\mathrm{a}}$ \\
\hline GP 3 & $64.51 \pm 2.33$ & $33.55 \pm 6.42^{\mathrm{b}}$ & 26.34 \\
\hline GP 4 & $68.28 \pm 3.14^{\mathrm{a}}$ & $62.81 \pm 3.81$ & $26.57 \pm 4.88^{\mathrm{b}}$ \\
\hline GP 5 & $74.09 \pm 3.03^{\mathrm{a}}$ & $37.11 \pm 2.86^{\mathrm{b}}$ & $27.20 \pm 3.30^{\mathrm{b}}$ \\
\hline \multicolumn{2}{|l|}{ Data represented as Mean \pm SEM; ${ }^{\mathrm{a}}=$ significantly higher compared to the control group, ${ }^{\mathrm{b}}=$ significantly lower compared to the control group }
\end{tabular}

Serum creatinine levels as shown in Table 3 was significantly higher $(p \leq 0.05)$ in the diabetic control group $(1.247 \pm 0.38$, $1.453 \pm 0.01$ and $1.622 \pm 0.02$ ) as against the normal control group $(0.516 \pm 0.03,0.567 \pm 0.03$ and $0.448 \pm 0.05)$ and the diabetic treated groups [Actovista $(0.588 \pm 0.04,0.580 \pm 0.00$ and $0.411 \pm 0.00)$, antioxidant supplement $(0.606 \pm 0.02,0.603$ \pm 0.02 and $0.565 \pm 0.01)$ and RiboCeine ${ }^{\varpi}(0.690 \pm 0.02,0.638 \pm$ 0.05 and $0.549 \pm 0.03)]$ respectively across the weeks $(4,8$ and $12)$. However, there was no observed statistical difference ( $p \geq$ 0.05) in the creatinine levels between the normal control group as against the various treatment groups.

Table 3 Serum creatinine level in normal and HFD-STZ induced NIDDM in albino rats administered antioxidant supplement.

\begin{tabular}{|l|l|l|l|}
\hline Creatinine & Week 4 & Week 8 & Week 12 \\
\hline GP 1 & $0.516 \pm 0.03$ & $0.567 \pm 0.03$ & $1.453 \pm 0.05$ \\
\hline GP 2 & $1.247 \pm 0.38^{\mathrm{a}}$ & $0.580 \pm 0.00$ & $0.01^{\mathrm{a}}$ \\
\hline GP 3 & $0.588 \pm 0.04$ & $0.603 \pm 0.02^{\mathrm{a}}$ & $0.565 \pm 0.01^{\mathrm{a}}$ \\
\hline GP 4 & $0.606 \pm 0.02^{\mathrm{a}}$ & $0.638 \pm 0.05^{\mathrm{a}}$ & $0.549 \pm 0.03^{\mathrm{a}}$ \\
\hline GP 5 & $0.690 \pm 0.02^{\mathrm{a}}$ & 0.00 \\
\hline Data represented as Mean \pm SEM; ${ }^{\mathrm{a}}=$ significantly higher compared to the control group, ${ }^{\mathrm{b}}=$ significantly lower compared to the control group. $^{2}$
\end{tabular}

For the serum bicarbonate levels as shown in Table 4, there was no significant difference $(p \geq 0.05$ ) observed in the diabetic control group $(33.04 \pm 7.39)$ relative to the diabetic treated groups $(27.40 \pm 2.72,26.12 \pm 0.73$ and $27.96 \pm 0.30)$ at the $4^{\text {th }}$ week. However, at the $8^{\text {th }}$ and $12^{\text {th }}$ week of treatment, the HFD/STZ-induced diabetic control group (34.64 \pm 4.52 and $38.50 \pm 0.50)$ had significantly higher ( $p \leq 0.05)$ serum bicarbonate levels compared to the normal control group
(30.77 \pm 0.60 and $27.33 \pm 0.33$ ), as well as the diabetic rats treated with Actovista (26.04 \pm 2.40 and $30.64 \pm 0.36)$, antioxidant supplement $(28.08 \pm 0.34$ and $27.06 \pm 1.38)$ and RiboCeine $^{\circledast}(28.25 \pm 1.88$ and $31.50 \pm 1.38)$ respectively. As observed, no significant difference $(p \geq 0.05)$ was observed in the bicarbonate levels of the normal group as against the various treated groups.

Table 4 Serum biocarbonate level in normal and HFD-STZ induced NIDDM in albino rats administered antioxidant supplement.

\begin{tabular}{|l|l|l|l|}
\hline Biocarbonate & Week 4 & Week 8 & Week 12 \\
\hline GP 1 & $31.51 \pm 3.14$ & $30.77 \pm 0.60$ & $27.33 \pm 0.33$ \\
\hline GP 2 & $33.04 \pm 7.39^{\mathrm{a}}$ & $34.64 \pm 4.52^{\mathrm{a}}$ & $38.50 \pm 0.50^{\mathrm{a}}$ \\
\hline GP 3 & $27.40 \pm 2.72^{\mathrm{b}}$ & $26.04 \pm 2.40^{\mathrm{b}}$ & $30.64 \pm 0.36$ \\
\hline
\end{tabular}




\begin{tabular}{|c|c|c|c|}
\hline GP 4 & $26.12 \pm 0.73^{b}$ & $28.08 \pm 0.34^{b}$ & $27.06 \pm 1.38$ \\
\hline GP 5 & $27.96 \pm 0.30$ & $28.25 \pm 1.88$ & $31.50 \pm 1.38^{a}$ \\
\hline
\end{tabular}

Table 5 revealed the electrolyte levels as at the $4^{\text {th }}, 8^{\text {th }}$ and $12^{\text {th }}$ weeks of treatment. The serum potassium levels as observed from the diabetic control group ( $2.54 \pm 0.24$ and 2.66 \pm 0.40 ) at the $4^{\text {th }}$ and $8^{\text {th }}$ week was significantly lower ( $p \leq$ $0.05)$ when compared to the normal control $(4.23 \pm 0.42$ and
$3.56 \pm 0.42)$ and treated groups. However, at $12^{\text {th }}$ week of study, the treated groups showed a significantly difference ( $p \leq$ 0.05 ) in serum potassium levels when compared across the various weeks.

Table 5 Serum potassium level in normal and HFD-STZ induced NIDDM in albino rats administered antioxidant supplement.

\begin{tabular}{|l|l|l|l|}
\hline Potassium & Week 4 & Week 8 & Week 12 \\
\hline GP 1 & $4.23 \pm 0.42$ & $3.56 \pm 0.42$ & $2.11 \pm 0.01^{\mathrm{b}}$ \\
\hline GP 2 & $2.54 \pm 0.24^{\mathrm{b}}$ & $3.66 \pm 0.40^{\mathrm{b}}$ & $3.90 \pm 0.01^{\mathrm{a}}$ \\
\hline GP 3 & $3.29 \pm 0.03$ & $3.33 \pm 0.05$ & $3.30 \pm 0.41$ \\
\hline GP 4 & $3.29 \pm 0.04^{\mathrm{b}}$ & $3.37 \pm 0.05$ & $3.27 \pm 0.17$ \\
\hline GP 5 & $3.30 \pm 0.04$ & & 3.13 \\
\hline Data represented as Mean \pm SEM; ${ }^{\mathrm{a}}=$ significantly higher compared to the control group, ${ }^{\mathrm{b}}=$ significantly lower compared to the control group.
\end{tabular}

The diabetic control group $(100.90 \pm 2.23,117.40 \pm 12.27$ and $99.32 \pm 0.32$ ) had significantly lower ( $\leq 0.05)$ serum sodium levels compared to the normal control group (120.38 \pm $2.11,159.88 \pm 3.99$ and $164.69 \pm 0.31$ ) as well as the diabetic treated groups (Table 6). There was no observed significant difference $(p \geq 0.05)$ in the sodium levels of the diabetic treated groups (actovista, antioxidant supplement and RiboCeine ${ }^{\oplus}$ ).

Table 6 Serum sodium level in normal and HFD-STZ induced NIDDM in albino rats administered antioxidant supplement.

\begin{tabular}{|l|l|l|l|}
\hline Sodium & Week 4 & Week 8 & Week 12 \\
\hline GP 1 & $120.38 \pm 2.11$ & $159.88 \pm 3.99$ & $164.69 \pm 0.31$ \\
\hline GP 2 & $100.90 \pm 2.23^{\mathrm{b}}$ & $139.40 \pm 12.27^{\mathrm{b}}$ & $139.32 \pm 0.32^{\mathrm{b}}$ \\
\hline GP 3 & $139.51 \pm 11.83^{\mathrm{a}}$ & $151.45 \pm 1.28$ & $158.32 \pm 9.35$ \\
\hline GP 4 & $130.04 \pm 7.64^{\mathrm{a}}$ & $142.36 \pm 1.00$ & $140.06 \pm 1.57$ \\
\hline GP 5 & $140.20 \pm 7.61^{\mathrm{a}}$ & \\
\hline \multicolumn{2}{|l|}{ Data represented as Mean \pm SEM; ${ }^{\mathrm{b}}=$ significantly higher compared to the control group, ${ }^{\mathrm{b}}=$ significantly lower compared to the control group } \\
\hline
\end{tabular}

The serum chloride level as shown in Table 7, reveals that the diabetic control group had significantly lower ( $p \leq 0.05$ ) levels compared to the diabetic treated groups. There was no observed significant difference $(p \geq 0.05)$ in the chloride levels between the diabetic treated groups (actovista, antioxidant supplement and RiboCeine ${ }^{\oplus}$ ) throughout the durations of study.

Table 7 Serum chloride level in normal and HFD-STZ induced NIDDM in albino rats administered antioxidant supplement.

\begin{tabular}{|l|l|l|l|}
\hline Chloride & Week 4 & Week 8 & Week 12 \\
\hline GP 1 & $138.29 \pm 1.12$ & $208.18 \pm 31.97$ & $166.21 \pm 0.21$ \\
\hline GP 2 & $119.91 \pm 1.43^{\mathrm{b}}$ & $94.80 \pm 1.96^{\mathrm{b}}$ & $155.45 \pm 0.27^{\mathrm{b}}$ \\
\hline GP 3 & $163.20 \pm 20.09^{\mathrm{a}}$ & $148.33 \pm 6.32$ & $158.43 \pm 9.96$ \\
\hline GP 4 & $153.16 \pm 5.58$ & $132.90 \pm 10.22^{\mathrm{b}}$ & 150 \\
\hline
\end{tabular}




\begin{tabular}{l|c|c|c|c|c|c|c|}
\hline GP 5 & $155.23 \pm 8.35$ & $140.76 \pm 3.21$ & $139.10 \pm 2.26$ \\
\hline
\end{tabular}

\section{Discussion}

Gluconeogensis is often times sustained by increased proteolysis which is associated with release of glucogenic amino acids that are deaminated in the liver, resulting in high urea levels [16]. A significant increase in serum urea and creatinine levels indicates an impaired renal function of diabetic animals [17]. The result showed a significant $(p<0.05)$ decrease in serum urea and creatinine concentration of the treated groups when compared to those of the normal and diabetic control groups, and the decrease was consistent all through the treatment duration (Tables 2 and 3). The observed elevation in serum urea and creatinine levels in the diabetic rats when compared to normal control and treated groups is consistent with other studies [18] which revealed that diabetes may expedite renal malfunctioning which might not be unrelated to oxidative stress and the stimulation of gluconeogenesis, resulting from insulin deficiency. Administration of the antioxidant supplement and the standard drugs significantly $(p \leq 0.05)$ decreased these markers in the treated groups when compared to the diabetic control group.

There was no observed statistically significant difference ( $p$ $\leq 0.05$ ) in biocarbonate and potassium levels of both the treated and untreated groups when compared with the results obtained from various weeks analysed. However, comparison between biocarbonate levels of the normal control and treated groups against the diabetic control group was significant ( $p \leq$ 0.05 ) lower, while that of potassium level was significantly ( $p \leq$ $0.05)$ higher.

One of the functions of the kidney is to maintain constant blood electrolyte concentrations despite physiologic body changes [19]. Hence, serum electrolyte values usually depicts renal functions or dysfunctions, since in cases of uncontrolled diabetes mellitus, kidney function is compromised. Glycosuria, which is a diagnostic feature of diabetes, causes dehydration via glucose osmotic dieuresis. Such dehydration is accompanied with severe loss of electrolytes including sodium, potassium, calcium, chloride and phosphates [20,21]. The result portrayed a decrease in serum electrolyte concentrations of diabetic control rats compared to the normal control and treated rats. This is consistent with reports of other researchers $[19,21,22]$. The antioxidant supplement and standard drug administration may have increased the serum electrolyte concentrations of the HFD-STZ induced diabetic rats, and this could be a useful tool in ameliorating the depletion in electrolyte levels under diabetic conditions.

These results show the ameliorative effects of the treatment regimen against diabetic-induced renal dysfunction in rats.

\section{Conclusion}

The study examined the effect of antioxidant supplementation and kidney function status of high fat diet and low dose streptozotocin induced type 2 diabetes mellitus in Wistar rats. The results therefore suggest that the supplement may be useful in ameliorating the effect of diabetes and oxidative stress related kidney dysfunction as well as the restoration of electrolyte levels resulting from diabetic conditions.

\section{References}

1. Adeshara KA, Diwan AG, Tupe RS (2016) Diabetes and complications: cellular signaling pathways, current understanding and targeted therapies. Curr Drug Targets 17: 1309-1328.

2. Arévalo-Lorido JC, Carretero-Gómez J, García-Sánchez F, MaciáBotejara E, Ramiro-Lozano JM, et al. (2016) Secondary hyperparathyroidism prevalence and profile, between diabetic and non-diabetic patients with stage 3 to 4 chronic kidney disease attended in internal medicine wards MiPTH study. Diabetes Metab Syndr 10:16-21.

3. Jagdale $A D$, Bavkar LN, More TA, Joglekar MM, Arvindekar AU (2016) Strong inhibition of the polyol pathway diverts glucose flux to protein glycation leading to rapid establishment of secondary complications in diabetes mellitus. J Diabetes Complications 30: 398-405

4. Badal SS, Danesh FR (2015). Diabetic nephropathy: Emerging biomarkers for risk assessment. Diabetes 64: 3063-3065.

5. Luo X, Wu J, Jing S, Yan LJ (2016) Hyperglycemic stress and carbon stress in diabetic glucotoxicity. Aging Dis 7: 90-110.

6. Muhl L, Moessinger C, Adzemovic MZ, Dijkstra MH, Nilsson I, et al. (2016) Expression of vascular endothelial growth factor (VEGF)-B and its receptor (VEGFR1) in murine heart, lung and kidney. Cell Tissue Res 365: 51-63.

7. Ozbek E (2012) Induction of oxidative stress in kidney. Int J Nephrol 2: 1.

8. Decoursey TE, Ligeti E (2005) Regulation and termination of NADPH oxidase activity. Cell Mol Life Sci 62: 2173-2193.

9. Ferreira SM, Lerner SF, Brunzini R, Evelson PA, Llesuy SF (2004) Oxidative stress markers in aqueous humor of glaucoma patients. Am J Ophthalmol 137: 62-69.

10. Srinivasan K, Viswanand B, Asrat L, Kaul CL, Ramarao P (2005) Combination of high-fat diet-fed and low dose of streptozotocin treated rat: A model for type 2 diabetes and pharmacological screening. Pharmacol Res 52: 313-320.

11. Weatherburn MW (1967) Phenol-hypochlorite reaction for determination of ammonia. Anal Chem 39: 971-974.

12. Bartels H, Bohmer M (1972) Quantitative determination of creatinine. Clinica Chimica Acta 37: 193. 
13. Forrester RL, Walaji LJ, Silvermann DA, Pierre KJ (1976) Enzymatic method for determination of $\mathrm{CO}_{2}$ in serum. Clin Chem 22: 243-245.

14. Henry RJ (1974) Clinical Chemistry. (2nd edn), Harper and Row Publishers, New York, USA. p: 643.

15. Tietz NW (1976). Fundamentals of clinical chemistry. (2nd edn), WB Saunders, Philadelphia, PA USA. p: 897.

16. Robinson G, Johnston DE (1997) Metabolic disorder: Diabetes. In: Mechanisms of disease. An introduction to clinical science. (1st edn Cambridge) Cambridge University Press, UK.

17. Shinde UA, Goyal RK (2003) Effect of chromium picolinate on histopathological alterations in Alloxan and neonatal alloxan diabetic rats. J Cell Mol Med 7: 322-329.

18. Atangwho IJ, Ebong PE, Eyong EU, Eteng MU, Obi AU (2007) Effect of Vernonia amygdalina Del. leaf on kidney function of diabetic rats. Int J Pharmacy 3: 142-148.
19. Prohp TP, Onoagbe IO (2014) Plasma electrolyte concentrations in normal and streptozotocin-induced diabetic rats treated with extracts of Triplochiton scleroxylon K. Schum. Am J Res Communication 2: 154-174.

20. Gaw A, Cowman RA, O'Reilly DS, Shepherd J (1995) Clinical Biochemistry: An Illustrated Color Text. Clin Biochem New York, USA.

21. Eteng MU, Ibekwe HA, Essien AD, Onyeama HP (2008) Effects of Catharanthus roseus on electrolyte derangement induced by chiopropamide (Diabinese) on normoglycemic albino wistar rats. Bioresources 62: 364-366.

22. Ikpi DE, Obembe AO, Nku CO (2009) Aqueous leaf extract of Rothmannia longflora improves basal metabolic rate and electrolyte parameters in alloxan- induced diabetic rats. Nigerian J Physiological Sci 24: 67-71. 